\title{
OBTENÇÃO DE ESTIRPES DE RIZÓBIO EFICIENTES NA FIXAÇÃO DE NITROGÊNIO EM TAMBORIL (Enterolobium contortisiliquum (Vell.) Morong) (Fabaceae)
}

\section{F. T. A. Moreira', D. R. Santos', G. H. Silva', L. S. Alencar'}

'Laboratório de Análise de Solos e Água - Universidade Federal de Campina Grande tiberiopcz@gmail.com - santos@cstr.ufcg.edu.br - girlanio_holanda@hotmail.com lyanne.florestal@hotmail.com

Artigo submetido em agosto/2012 e aceito em setembro/2012

\section{RESUMO}

Através da inoculação de rizóbios em plantas é possível produzir mudas autosuficientes na nutrição de nitrogênio aumentando a produtividade agrícola dos solos. Este estudo objetivou avaliar a eficiência de estirpes de rizóbio em solos de diferentes microregiões da Paraíba pela fixação biológica de nitrogênio em Tamboril. Os tratamentos utilizados foram: inoculação com rizóbio isolados das diferentes microregiões e testemunha (sem inoculação). Os isolados rizobianos NFB03, NFB07, NFB08, NFB09, NFB10, NFB11, NFB12, NFB14, NFB15, NFB16, NFB17, NFB18 e NFB19 foram os mais eficientes na promoção do crescimento do Tamboril.

PALAVRAS-CHAVE: Isolados Bacterianos, Crescimento, Microorganismos, Nódulo.

\section{OBTAINMENT OF EFFICIET RHIZOBIAL STRAINS FOR NITROGEN FIXATION IN THE TAMBORIL (Enterolobium contortisiliquum (Vell.) Morong) (Fabaceae)}

\section{ABSTRACT}

Through the inoculation of rhizobia inplants is possible produce seedlings self-sufficient in nitrogen nutrition increasing the agricultural productivity of soils. This study aimed to evaluate the efficiency of rhizobia strains in soils from different microregions of Paraiba by biological nitrogen fixation in Tamboril. The treatments were: inoculation with rhizobia isolated from different microregions and control (without inoculation). The rhizobials isolates NFB03, NFB07, NFB08, NFB09, NFB10, NFB11, NFB12, NFB14, NFB15, NFB16, NFB17, NFB18 and NFB19 were the most efficient promoting growth of Tamboril.

KEY-WORDS: Bacterial Isolates, Growth, Microorganisms, Nodule. 


\section{OBTENÇÃO DE ESTIRPES DE RIZÓBIOS EFICIENTES NA FIXAÇÃO DE NITROGÊNIO EM TAMBORIL (Enterolobium contortisiliquum (Vell.) Morong) (Fabaceae)}

\section{INTRODUÇÃO}

A transmissão das bactérias diazotróficas, como os rizóbios, para as plantas pode ocorrer através de diversas formas dentre elas se destacam, esporos de FMAs (Fungos Micorrízicos Arbusculares) (Bhowmik \& Singh, 2004; LI \& Strzelczyk, 2000) e pela colonização bacteriana em hifas extra radiculares de FMAs (Toljander et al., 2006).

A inoculação de bactérias diazotróficas possui eficiência comprovada pela pesquisa em diferentes espécies, conferindo benefícios na nutrição, promoção de crescimento e proteção das mudas durante o transplantio (Borges et al., 2003).

O nitrogênio de forma contínua a médio e longo prazo se torna disponível através da associação de plantas com microrganismos procariontes, que constituem uma grande variedade de bactérias, algumas de vida livre e outras que vivem em simbiose com plantas, capazes de reduzir o $\mathrm{N}$ atmosférico à $\mathrm{NH}_{3}$, forma utilizada pelos vegetais (Faria, 2002).

Dessa forma a seleção de estirpes eficientes de rizóbios é possível produzir mudas de essências florestais bem noduladas, com crescimento mais rápido e maior resistência às condições de campo. A simbiose planta $\mathrm{x}$ bactéria diazotróficas aumenta a capacidade da planta em incorporar $\mathrm{C}$ e $\mathrm{N}$ no solo, sendo mais eficiente na absorção de nutrientes tornando-se mais resistentes a estresses ambientais (Siqueira \& Franco, 1988).

Por outro lado, a introdução de inoculantes contendo rizóbios eficientes, é dificultada, pois as estirpes nativas são, em geral, muito competitivas e de baixa eficiência na fixação do $\mathrm{N}_{2}$ (Santos, 2003). Assim, estratégias que avaliem a composição e a contribuição para a FBN por estirpes de rizóbio do solo em que se pretende introduzir o inoculante, são de grande importância (Zilli, 2001; Raposeiras et al., 2006; Pelegrin et al., 2009; Kaneko et al., 2010).

O Tamboril (Enterolobium contortisiliquum) é uma espécie arbórea pertencente à família Fabaceae bem adaptada a região Nordeste, possui copa ampla e frondosa, proporcionando ótima sombra durante o verão. É usada para reflorestamento de áreas degradadas em áreas de preservação permanente como também em plantios mistos, principalmente por seu rápido crescimento (Lorenzi, 1998).

Outros trabalhos mostram que as leguminosas de porte arbóreo vêm sendo amplamente utilizadas em trabalhos de recuperação de áreas degradadas, por apresentarem sistema radicular profuso (Franco et al., 1992), tolerância à acidez do solo e estresse de temperatura por contribuírem com deposição de matéria orgânica de baixa relação C/N (Franco et al., 1992).

A família Fabaceae (Leguminosa) é componente bem representado na flora de diversos ecossistemas brasileiros. Vários trabalhos confirmam a presença vários gêneros e espécies nodulíferas nos vários ecossistemas, como na flora amazônica e no Cerrado (Souza et al., 1997; Silva et al., 1989); porém no bioma Caatinga são escassos. 
Em termos econômicos, sua importância também e expressiva, leguminosas nativas brasileiras são utilizados para produção de madeira, energia, celulose, extração de fitoquímicos, na alimentação humana e animal, recuperação de áreas degradadas, etc. Assim, várias espécies nativas da Caatinga apresentam alto valor sócio-econômico para a população, sendo por isso, bastante pressionadas (Sampaio et al., 2005).

Este trabalho teve como objetivo avaliar o desenvolvimento, após inoculação de rizóbios eficientes para fixação biológica de nitrogênio, em Tamboril (Enterolobium contorticiliquum).

\section{MATERIAL E MÉTODOS}

O trabalho foi realizado em telado no Viveiro da Unidade Acadêmica de Engenharia Florestal da UFCG, Campus de Patos - PB. Com coordenadas geográficas de $07^{\circ} 01^{\prime}$ de latitude sul e $37^{\circ} 15^{\prime}$ de longitude oeste, com altitude de 234 metros.

O clima da região, segundo a classificação de Köppen, se enquadra no tipo Bsh, semiárido, com médias térmicas anuais superiores a $25^{\circ} \mathrm{C}$ e pluviosidade média anual inferior a $1.000 \mathrm{~mm}$ $\mathrm{ano}^{-1}$, com chuvas irregulares (Souto, 2006).

O substrato utilizado foi a vermiculita. Esta foi esterilizada, utilizando-se autoclave (120ㄷ; $1,0 \mathrm{~atm})$, para posterior preenchimento de copos plásticos de $250 \mathrm{~cm}^{3}$, procedendo-se posteriormente a adição de $50 \mathrm{~cm}^{3}$ (solo inóculo) em seus respectivos vasos como as amostras de solos $(0-20 \mathrm{~cm})$ provenientes dos municípios da região semiárida em estudo.

Os solos coletados em áreas das diferentes microrregiões do semiárido paraibano estão caracterizados conforme tabela 1 abaixo.

O meio de cultura utilizado no isolamento, multiplicação e armazenamento dos isolados rizóbianos foi o extrato de levedura e manitol (YMA, Yeast Manitol Agar), conforme composição apresentada na tabela 2. O meio YMA sólido, YMA liquido com adição do indicador Azul de Bromotimol, que foi utilizado na identificação da reação de excreção da bactéria e YMA sólido sem indicador, respectivamente.

Realizado o processo de homogeneização das soluções, a mesma foi completada para $1000 \mathrm{ml}$ com água destilada e ajustando-se o pH do mesmo para 6,8. Em seguida este foi estilizado em autoclave a $120^{\circ} \mathrm{C}$ por 20 minutos.

Tabela 1: Caracterização das amostras de solo utilizadas com inóculo.

\begin{tabular}{|c|c|c|c|c|c|c|c|c|c|c|}
\hline Origem & Amost. & pH & $\mathbf{P}$ & $\mathrm{Ca}$ & $\mathrm{Mg}$ & $\mathbf{K}$ & $\mathrm{Na}$ & $\begin{array}{c}\mathrm{H} \\
+\mathrm{Al}\end{array}$ & СТC & V \% \\
\hline & & $\begin{array}{l}\mathrm{CaCl}_{2} \\
0,01 \mathrm{M}\end{array}$ & $\underset{/ \mathrm{cm}^{3}}{\mu}$ & \multicolumn{6}{|c|}{$\mathrm{cmol}_{\mathrm{c}} \mathrm{dm}^{-3}$} & \\
\hline Nupeárido - Patos & 258 & 5,73 & 23,7 & 6,0 & 4,0 & 0,26 & 1,34 & 1,2 & 12,8 & 90,6 \\
\hline Nupeárido - Patos & 259 & 5,58 & 44,6 & 4,6 & 4,0 & 0,22 & 1,29 & 1,3 & 11,4 & 88,6 \\
\hline Nupeárido - Patos & 260 & 5,64 & 38,5 & 6,2 & 4,8 & 0,19 & 1,22 & 1,1 & 13,5 & 91,9 \\
\hline Nupeárido - Patos & 261 & 5,72 & 36,4 & 6,2 & 5,2 & 0,24 & 1,33 & 1,0 & 14,0 & 92,8 \\
\hline Nupeárido - Patos & 267 & 5,24 & 113,7 & 4,0 & 2,8 & 0,22 & 1,57 & 1,3 & 9,9 & 86,9 \\
\hline Nupeárido - Patos & 268 & 5,17 & 91,9 & 5,2 & 3,4 & 0,21 & 1,54 & 1,7 & 12,1 & 85,9 \\
\hline Nupeárido - Patos & 269 & 5,35 & 159,7 & 4,6 & 3,0 & 0,26 & 1,65 & 1,5 & 11,0 & 86,4 \\
\hline
\end{tabular}

HOLOS, Ano 28, Vol 4 


\begin{tabular}{|c|c|c|c|c|c|c|c|c|c|c|}
\hline Nupeárido - Patos & 270 & 5,53 & 194,9 & 4,8 & 3,2 & 0,29 & 1,80 & 1,5 & 11,6 & 87,1 \\
\hline Nupeárido - Patos & 271 & 5,71 & 25,2 & 4,4 & 1,6 & 0,21 & 1,60 & 1,1 & 8,9 & 87,7 \\
\hline UFCG - Patos & 280 & 5,96 & 56,1 & 2,8 & 2,2 & 0,32 & 1,89 & 0,9 & 8,1 & 88,9 \\
\hline UFCG - Patos & 281 & 5,88 & 14,3 & 6,2 & 3,8 & 0,92 & 3,06 & 1,4 & 15,4 & 90,9 \\
\hline UFCG - Patos & 282 & 5,83 & 27,1 & 4,2 & 3,6 & 0,68 & 2,58 & 1,2 & 12,3 & 90,2 \\
\hline UFCG - Patos & 283 & 5,53 & 70,0 & 4,0 & 2,6 & 0,45 & 2,30 & 1,3 & 10,6 & 87,8 \\
\hline UFCG - Patos & 284 & 6,41 & 86,7 & 5,0 & 3,2 & 0,83 & 3,17 & 0,9 & 13,1 & 93,1 \\
\hline UFCG - Patos & 285 & 6,45 & 83,0 & 4,8 & 3,2 & 0,27 & 3,42 & 0,9 & 12,6 & 92,9 \\
\hline UFCG - Patos & 286 & 6,53 & 79,3 & 5,2 & 4,0 & 0,22 & 2,98 & 1,0 & 13,4 & 92,5 \\
\hline UFCG - Patos & 287 & 6,12 & 135,5 & 6,0 & 4,4 & 0,69 & 3,21 & 1,1 & 15,4 & 92,9 \\
\hline UFCG - Patos & 288 & 6,01 & 108,9 & 8,0 & 6,0 & 0,50 & 2,53 & 1,1 & 18,1 & 93,9 \\
\hline UFCG - Patos & 289 & 5,74 & 12,2 & 4,6 & 2,0 & 0,60 & 2,43 & 1,3 & 10,9 & 88,1 \\
\hline Faz. Enjeitado - Patos & 245 & 6,08 & 21,9 & 4,4 & 2,2 & 0,31 & 1,76 & 1,3 & 10,0 & 87,0 \\
\hline Faz. P.Baixo - Teixeira & 263 & 5,87 & 11,4 & 4,0 & 3,6 & 0,33 & 1,60 & 1,2 & 10,7 & 88,8 \\
\hline Faz. P.Baixo - Teixeira & 264 & 5,91 & 6,1 & 4,4 & 2,4 & 0,23 & 1,38 & 1,1 & 9,5 & 88,4 \\
\hline Sít. Riacho - Texeira & 246 & 6,00 & 13,9 & 2,2 & 1,0 & 0,29 & 1,22 & 1,0 & 5,7 & 82,5 \\
\hline Sít. Riacho - Texeira & 247 & 6,11 & 58,9 & 6,0 & 3,0 & 0,21 & 1,52 & 1,2 & 11,9 & 89,9 \\
\hline Sit. Boa Vista - Teixeira & 272 & 5,61 & 14,3 & 5,6 & 3,8 & 0,48 & 2,36 & 1,2 & 13,4 & 91,1 \\
\hline Santa Tereza - Teixeira & 291 & 6,33 & 86,7 & 6,8 & 2,4 & 1,64 & 3,91 & 0,6 & 15,4 & 96,1 \\
\hline $\begin{array}{l}\text { Riacho Moças - } \\
\text { Teixeira }\end{array}$ & 254 & 5,30 & 11,2 & 4,2 & 1,8 & 0,48 & 1,58 & 2,5 & 10,6 & 76,3 \\
\hline Lagoa Alves - Condado & 249 & 5,93 & 47,9 & 4,4 & 3,2 & 0,29 & 1,33 & 1,1 & 10,3 & 89,3 \\
\hline Lagoa Alves - Condado & 250 & 6,41 & 58,1 & 7,2 & 4,2 & 0,24 & 1,13 & 0,9 & 13,7 & 93,4 \\
\hline Lagoa Alves - Condado & 251 & 6,60 & 56,0 & 3,2 & 2,6 & 0,28 & 5,20 & 0,9 & 12,2 & 92,6 \\
\hline Lagoa Alves - Condado & 252 & 6,59 & 8,6 & 2,8 & 2,2 & 0,14 & 1,13 & 1,0 & 7,3 & 86,2 \\
\hline Sit. Jardim - Emas & 265 & 5,97 & 15,0 & 5,0 & 4,4 & 0,07 & 1,34 & 0,9 & 11,7 & 92,3 \\
\hline Sit. Jardim - Emas & 266 & 5,56 & 25,2 & 4,8 & 4,2 & 0,43 & 1,76 & 1,3 & 12,5 & 89,6 \\
\hline Pedra Trepada - Emas & 262 & 6,05 & 40,8 & 8,4 & 7,6 & 0,14 & 1,89 & 1,0 & 19,0 & 94,7 \\
\hline C. Alegre - S. Mamede & 248 & 6,20 & 11,1 & 5,2 & 3,0 & 0,13 & 1,09 & 1,1 & 10,5 & 89,5 \\
\hline Angola - São Mamede & 257 & 6,22 & 772,5 & 11 & 7,8 & 0,57 & 2,37 & 1,1 & 23,0 & 95,2 \\
\hline Sit. Trincheira - Pombal & 290 & 6,26 & 155,3 & 5,8 & 4,2 & 0,16 & 1,95 & 1,2 & 13,3 & 91,0 \\
\hline $\begin{array}{l}\text { Formiga - S.José de } \\
\text { Princesa }\end{array}$ & 256 & 6,10 & 27,9 & 7,0 & 4,4 & 0,37 & 2,56 & 1,4 & 15,7 & 91,1 \\
\hline $\begin{array}{l}\text { Sit. Fumo - Pedra } \\
\text { Branca }\end{array}$ & 253 & 6,24 & 3,3 & 6,0 & 4,0 & 0,22 & 1,20 & 1,3 & 12,7 & 89,8 \\
\hline
\end{tabular}

Tabela 2: Meio de cultivo básico utilizado para isolamento e multiplicação dos isolados bacterianos.

\begin{tabular}{|l|c|c|}
\hline \multicolumn{1}{|c|}{ COMPONENTES } & ESTOQUE & QUANTIDADES \\
\hline $\mathrm{K}_{2} \mathrm{PO}_{4}$ & $10 \%$ & $1 \mathrm{ml}$ \\
\hline $\mathrm{KH}_{2} \mathrm{PO}_{4}$ & $10 \%$ & $2 \mathrm{ml}$ \\
\hline $\mathrm{MgSO}_{4}$ & $10 \%$ & $1 \mathrm{ml}$ \\
\hline $\mathrm{NaCl}$ & $10 \%$ & $0,5 \mathrm{ml}$ \\
\hline Azul de Bromotimol & $0,5 \%$ (Sol. Alcoólica) & $2,5 \mathrm{ml}$ \\
\hline Extrato de levedura & $10 \%$ & $100 \mathrm{ml}$ \\
\hline Açúcar cristal & - & $10 \mathrm{~g}$ \\
\hline Agar em pó & - & $7,5 \mathrm{~g}$ \\
\hline $\mathrm{H}_{2} \mathrm{O}$ destilada & - & $500 \mathrm{ml}$ \\
\hline
\end{tabular}


Utilizaram-se recipientes de vidro com $50 \mathrm{~mL}$ do meio de cultura YMA líquido com azul de bromotimol para a produção dos inoculantes com os isolados bacterianos puros. Após repicagem das cepas para o meio, estes foram incubados em estufa ( $\left.32^{\circ} \mathrm{C}\right)$ por 72 horas. Para a produção de inoculantes foram multiplicados e caracterizados quanto à reação (Tabela 3).

Tabela 3. Caracterização da reação dos isolados bacterianos utilizados em de cultura.

\begin{tabular}{|c|c|}
\hline REAÇÃo & \multicolumn{1}{|c|}{ IDENTIFICAÇÃo } \\
\hline \multirow{3}{*}{ Ácida } & UFCG02(245), UFCG03(250), UFCG07(260), UFCG08(261), UFCG09(262), \\
& UFCG10(263), UFCG11(264), UFCG12(265), UFCG13(270), UFCG14(280), \\
& UFCG15(281)), UFCG16(285), UFCG17(287), UFCG18(289) \\
\hline Básica & UFCG01(234), UFCG04(251), UFCG05(257)), UFCG06(258), UFCG19(290) \\
\hline
\end{tabular}

Utilizaram-se vasos de Leonard com capacidade de $1 \mathrm{~L}$ em cada compartimento. Os tratamentos utilizados foram: inoculação com rizóbio e testemunha absoluta (sem inoculação). 0 compartimento superior dos vasos foi preenchido com areia lavada e autoclavada $\left(120{ }^{\circ} \mathrm{C}\right.$ durante 30 minutos), e o inferior com solução nutritiva livre desse nutriente (Weaver \& Frederick, 1982).

As sementes de Tamboril foram desinfectadas em álcool etílico (70\%) e hipoclorito de sódio (2\%) durante 5 minutos.

Estas sementes tiveram a quebra de dormência pelo método descrito por Fowler \& Bianchetti (2000), onde se utilizou ácido sulfúrico $\left(\mathrm{H}_{2} \mathrm{SO}_{4}\right)$ durante um período de 30 minutos, em seguida, todas foram lavadas em água corrente para remoção do excesso do ácido e posteriormente postas para germinar em bandejas de polipropileno com papel de filtro e algodão umedecido estéril, e incubado em câmara de germinação à temperatura ambiente (25-30ㅇ C) até que as radículas atingissem $0,5-1,0 \mathrm{~cm}$ de comprimento.

As sementes pré-geminadas foram repicadas para os vasos de Leonard (3 por vaso) com substrato esterilizado.

A inoculação com os isolados bacterianos foi realizada com a distribuição de $1,0 \mathrm{ml}$ de cultura nos respectivos vasos devidamente identificados. No quinto dia após a germinação, foi realizado o desbaste conduzindo-se apenas uma planta por vaso.

Todos os tratamentos receberam solução nutritiva livre de nitrogênio (Norris \& Date, 1976). A cada sete dias foi reposta a água evaporada adicionando água estéril.

As plantas foram coletadas aos 60 dias após a repicagem, sendo avaliados o número de massa dos nódulos secos e a massa da matéria seca da parte aérea e raiz de cada planta (g).

A matéria seca da parte aérea (MSPA) e a matéria seca dos nódulos (MSN) foram obtidos após secagem desses materiais em estufa a $65-70{ }^{\circ} \mathrm{C}$ por 72 horas.

O delineamento experimental utilizado foi o de blocos ao acaso, com três repetições. Cada tratamento foi constituído de uma estirpe, além de dois tratamentos adicionais, uma testemunha nitrogenada, e uma testemunha não nitrogenada. 
Os dados obtidos foram submetidos à análise da variância e comparação de média pelo teste de Scott-Knott a $5 \%$ de probabilidade. As análises foram realizadas pelo programa computacional Assistat-beta 7.4 (Santos \& Silva, 2007).

\section{RESULTADOS E DISCUSSÕES}

A produção de massa seca na parte aérea do tamboril diferiu entre os isolados rizobianos na inoculação (Figura 1).

Observou-se que plantas inoculadas os isolados NFB03, NFB07, NFB08, NFB09, NFB10, NFB11, NFB12, NFB14, NFB15, NFB16, NFB17, NFB18 e NFB19 apresentaram produção superior do que a testemunha, sem inoculação. Estas respostas indicam que as presenças destas bactérias induziram melhor crescimento do tamboril, possivelmente, devido ao maior aporte de Nitrogênio proveniente dos isolados mais eficientes.

Resultados similares foram observados em outro estudo onde, verificou-se que leguminosas como bracatinga, acácia e sabiá apresentaram crescimento superior ao eucalipto (espécies de rápido crescimento) (Franco et al., 1991), e até mesmo de crescimento superior em acácia àquelas que receberam N-mineral no viveiro (Faria et al., 1996).

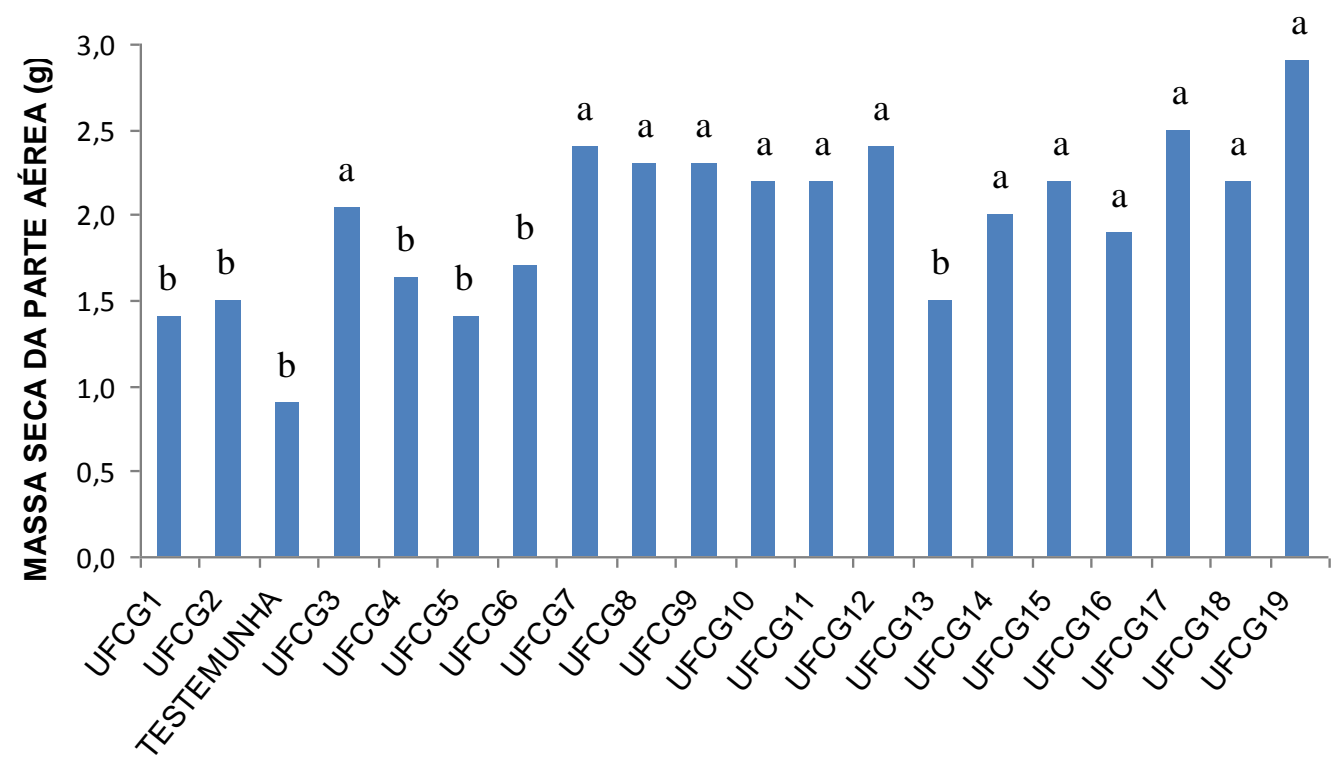

ISOLADOS RIZOBIANOS

Figura 1: Produção de massa seca da parte aérea de tamboril aos 60 dias inoculadas com isolados rizobianos de diferentes origens.

*Colunas seguidas pela mesma letra não diferem estatisticamente entre si pelo teste de ScottKnott a $5 \%$ de probabilidade 
As respostas dos isolados na produção da matéria seca das raízes foram mais modestas, apenas NFB06, NFB07, NFB09, NFB16 e NFB19 apresentaram diferenças significativas em relação a testemunha (Figura 2). Provavelmente devido ao desenvolvimento radicular ser menos inluenciado pela presença direta do rizóbio ou de necessitarem de rizóbios mais eficientes na fixação do N, como ratifica as respostas observadas para estes mesmos isolados na produção de massa seca.

Resultados semelhantes foram encontrados por Araujo et al. (2010) ao estudarem as respostas de inóculos de rizóbios em mudas de Leucena e feijão-cupi onde a matéria seca das raízes de ambas as espécies aumentou com a inoculação.

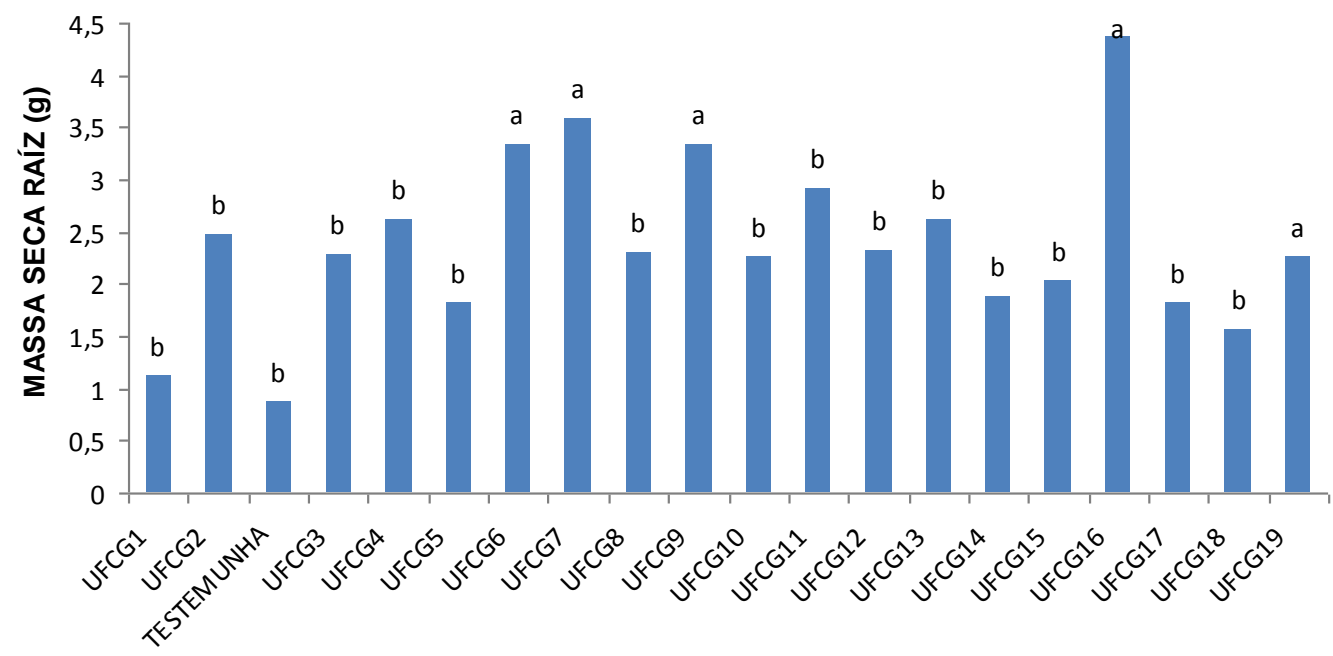

ISOLADOS RIZOBIANOS

\section{Figura 2: Produção de massa seca da raiz de tamboril aos 60 dias inoculadas com isolados} bacterianos de diferentes origens.

*Colunas seguidas pela mesma letra não diferem estatisticamente entre si pelo teste de ScottKnott a $5 \%$ de probabilidade

Observou-se que plantas inoculadas os isolados NFB01, NFB03, NFB04, NFB06, NFB07, NFB08, NFB09, NFB10, NFB12, NFB14, NFB15, NFB16 e NFB19 apresentaram número de nódulos radiculares superiores do que a testemunha, sem inoculação e aos demais isolados, figura 3. Já para a massa nodular exceto pela ausência de NFB01, NFB12 e da presença da NFB16 as demais apresentaram respostas semelhantes ao número de nódulos, figura 4.

Estas respostas corroboram com outros resultados observados por Ascheffer Basso et al. (2000) ao estudarem em plantas de Adesmia araujoi para a produção de massa seca da parte aérea, relatando o beneficio diferenciado entre os inoculantes rizobianos, sugerindo melhor associação destes isolados e a planta hospedeira Especificidade hospedeira, que é resultante do processo de reconhecimento entre a planta e a bactéria, que também foi relatada em outras espécies arbóreas (Campelo \& Dobereiner, 1969).

Sendo assim, através da continuidade do processo de seleção dos isolados: NFB03, NFB07, NFB08, NFB09, NFB10, NFB11, NFB12, NFB14, NFB15, NFB16, NFB17, NFB18 e NFB19 é possível a obtenção de estirpes eficientes de rizóbio para tamboril. 


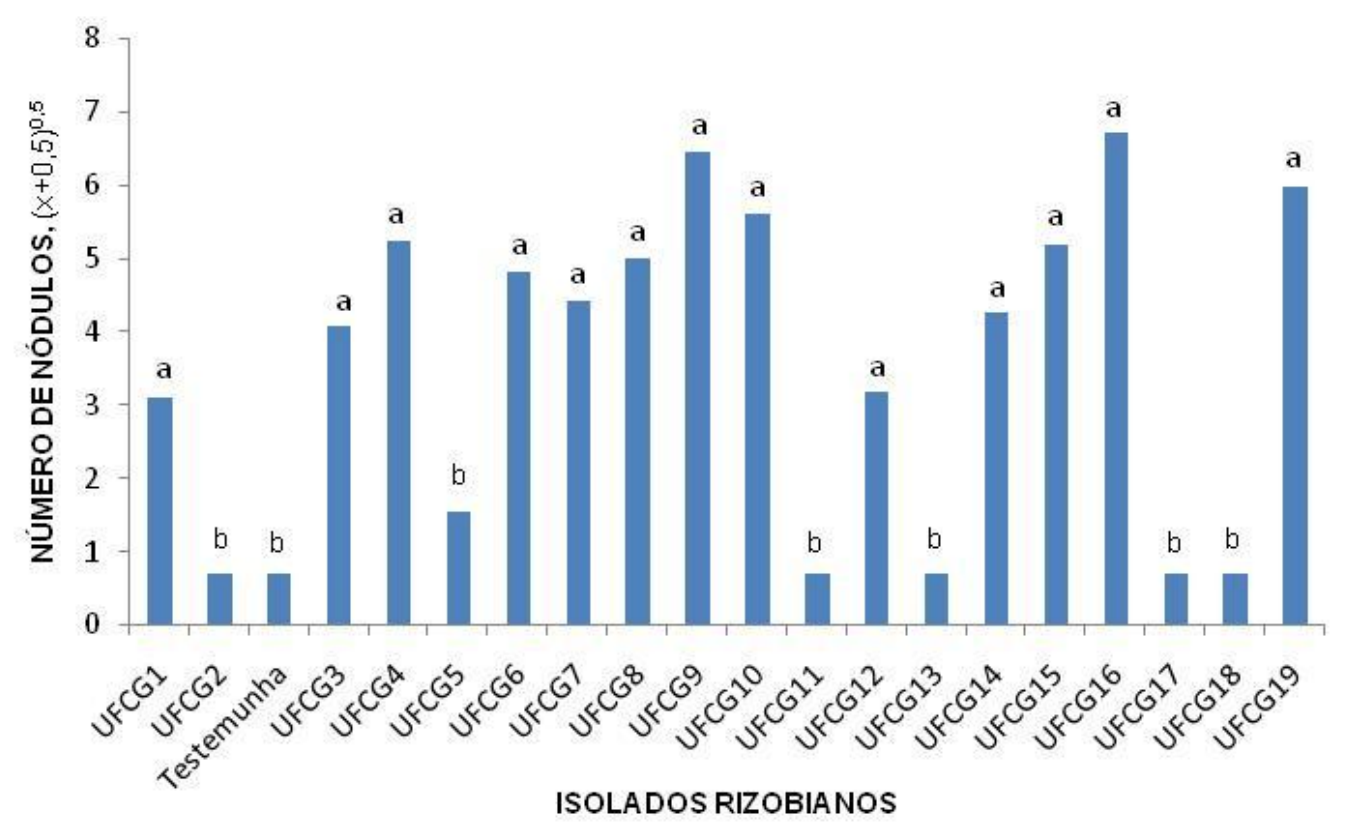

Figura 3: Número de nódulus radiculares de tamboril aos 60 dias inoculadas com isolados bacterianos de diferentes origens.

*Colunas seguidas pela mesma letra não diferem estatisticamente entre si pelo teste de ScottKnott a 5\% de probabilidade

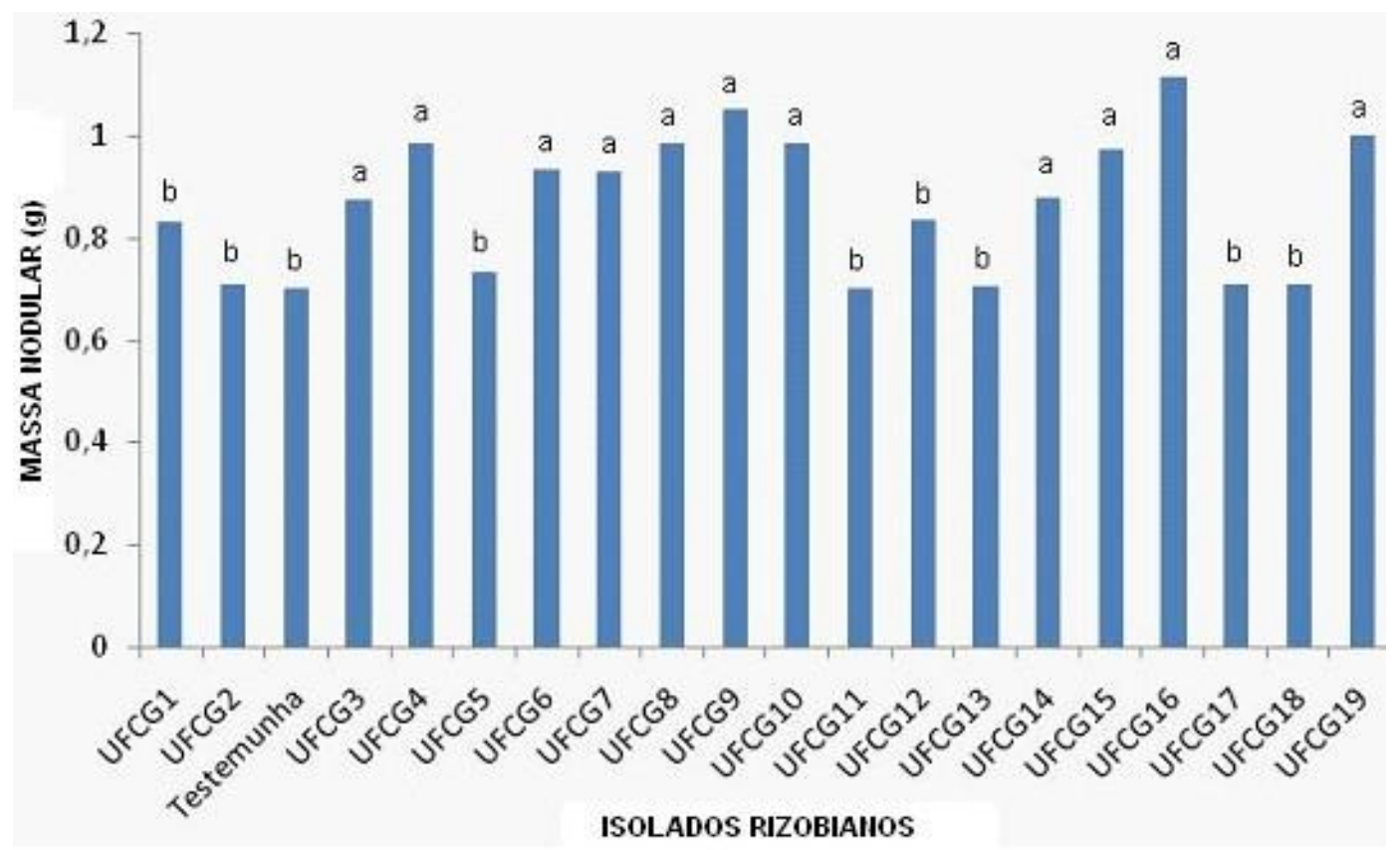

Figura 4: Massa de nódulus radiculares de tamboril aos 60 dias inoculadas com isolados bacterianos de diferentes origens.

*Colunas seguidas pela mesma letra não diferem estatisticamente entre si pelo teste de ScottKnott a $5 \%$ de probabilidade 


\section{CONCLUSÃO}

Os isolados rizobianos NFB03, NFB07, NFB08, NFB09, NFB10, NFB11, NFB12, NFB14, NFB15, NFB16, NFB17, NFB18 e NFB19 foram os mais eficientes para promoção do desenvolvimento do Tamboril através da fixação biológica do nitrogênio atmosférico.

\section{AGRADECIMENTOS}

Ao CNPq pela bolsa de Iniciação Científica.

\section{REFERÊNCIAS BIBLIOGRÁFICAS}

1. ARAÚJO, A. S. F. I; CARNEIRO, R. F. V.; BEZERRA, A. A. C.; ARAÚJO, F. F. Coinoculação rizóbio e Bacillus subtilis em feijão-caupi e leucena: efeito sobre a nodulação, a fixação de $\mathrm{N}_{2}$ e o crescimento das plantas. Ciência Rural, vol. 40, núm. 1, 2010.

2. ASCHEFFER-BASSO, S. M.; CARNEIRO, C. M.; VOSS, M. Nodulação e Fixação Biológica de Nitrogênio. Rev. Brasileira de Agrociência, v.6 no1, 2000.

3. BHOWMIK, S. N.; SINGH, C. S. Mass multiplication of AM inoculum; effect of plant growthpromoting rhizobacteria and yeast in rapid culturing of Glomus mosseae. Current Science, Bangalore, v.86, p.705-709, 2004.

4. BORGES, A. L.; CORDEIRO, Z. J. M.; FRANCELLI, M.; SOUZA, L. S.; SILVA, S. O.; COELHO, E. F.; LIMA, M. B.; MEDINA, V. M.; RITZINGER, C. H. S. P.; FOLEGATTI, M. I. S.; SOUZA, A. S.; MESQUITA, A. L. M.; CARVALHO, J. E. B.; TRINDADE, A. V.; ALMEIDA, C. O.; MATOS, A. P.; MEISSNER FILHO, P. E.; FREIRE, F. C. O.; BARROS, L. M.; CRISÓSTOMO, L. A.; MOSCA, J. L.; CARVALHO, A. C. P. P. Cultivo da banana para o Agropólo Jaguaribe-Apodi, Ceará. Cruz das Almas: Embrapa Mandioca e Fruticultura, 2003.

5. CAMPELO, A.B.; DOBEREINER, J. Estudo sobre a inoculação cruzada de algumas leguminosas florestais. Pesq. Agrop. Bras., v. 4, p..67-72, 1969.

6. FARIA, M.P.; SIQUEIRA, J.O.; VALE, F.R. do; CURI, N. Crescimento inicial da Acácia em resposta a fósforo, nitrogênio, fungo micorrízico e rizóbio. R. B. Ci. Solo: Campinas, v. 20, p. 209-216, 1996.

7. FARIA, S.M. Obtenção de estirpes de rizóbio eficientes na fixação de nitrogênio para espécies florestais. Seropédica: Embrapa Agrobiologia, Jan. 2002. 16p. (Embrapa-CNPAB. Documentos, 134).

8. FOWLER, A.J.P.; BIANCHETTI, A. Dormência em sementes florestais. Colombo: Embrapa Florestas, 2000. 27p. Embrapa Florestas. Documentos, 40.

9. FRANCO, A. A.; CAMPOS NETO, D.C.; CUNHA, C.O.; CAMPELLO, E.F.; MONTEIRO, E.M.S.; SANTOS, C.J.S.; FONTES, A.M.; FARIA, S.M. de Revegetação de solos degradados. In: WORKSHOP SOBRE RECUPERAÇÃO DE ÁREAS DEGRADADAS, I., 1990, Itaguaí-RJ. Anais... Itaguaí: UFRRJ, Departamento de Ciências Ambientais, 1991. p. 133-156. 
10. FRANCO, A.A.; CAMPELLO, E.F.; SILVA, E.M.R. da; FARIA, S.M. de . Revegetação de solos degradados. Seropédica: EMBRAPA-CNPBS, 1992. 11p.(EMBRAPA CNPBS. Comunicado Técnico, 9).

11. KANEKO, F.H.; ARF, O.; GITTI, D. de C.; ARF, M.V.; FERREIRA, J.P.; BUZETTI, S. Mecanismos de abertura de sulcos, inoculação e adubação nitrogenada em feijoeiro em sistema plantio direto. Bragantia, v.69, p.125-133, 2010.

12. LI, C.Y.; STRZELCZYK, E. Belowground microbial process underpin forest productivity. Phyton, Buenos Aires, v.40, p.129-134, 2000.

13. LORENZI, H. Árvores Brasileiras: manual de identificação e cultivo de plantas arbóreas nativas do Brasil. v. 01, p. 177, 1998.

14. NORRIS, D.O..\& DATE, R.A. Legume bacteriology. In: SHAW, N.H., BRYAN, W.W. (Eds.) Tropical pasture research - principles and methods. Brisbane: CAB. 1976. p.134-173.

15. Pelegrin, R. de; MERCANTE, F.M.; OTSUBO, I.M.N.; OTSUBO, A.A. Resposta da cultura do feijoeiro à adubação nitrogenada e à inoculação com rizóbio. Revista Brasileira de Ciência do Solo, v.33, p. 219-226, 2009.

16. RAPOSEIRAS, R.; MARRIEL, I.E.; MUZZI, M.R.S.; PAIVA, E.; PEREIRA FILHO, I.A.; CARVALHAIS, L.C.; PASSOS, R.V.M.; PINTO, P.P.; SÁ, N.M.H. de. Rhizobium strains competitiveness on bean nodulation in Cerrado soils. Pesquisa Agropecuária Brasileira, v.41, p.439-447, 2006.

17. SAMPAIO, E.V.S.; PAREYN, F.G.C. FIGUEIROA, J.M.; SANTOS JUNIOR, A.G.(Eds.). Espécies da flora nordestina de importância econômica potencial. Recife: Associação de Plantas do Nordeste/MMA. 2005. 331p.

18. SANTOS e SILVA, F.A. ASSISTAT - beta 7.4. Campina Grande: 2007.

19. SANTOS, A.B. dos; FAGERIA, N.K.; SILVA, O.F. da; MELO, M.L.B. de. Resposta do feijoeiro ao manejo de nitrogênio em várzeas tropicais. Pesquisa Agropecuária Brasileira, v.38, p.1265 1271, 2003.

20. SILVA, M.F.; CARREIRA, L.M.M.; TAVARES, A.S.; RAIBEIRO, I.C.; JARDIM, M.A.G.; LOBO, M.G.A.; OLIVEIRA, J. As leguminosas da Amazônia Brasileira - Lista previa. Acta Bot. Anais do XXXIX CONGRESSO NACIONAL DE BOTÂNICA. 2.193-237, 1989.

21. SIQUEIRA, J.O. \& FRANCO, A.A. Biotecnologia do Solo: Fundamentos e Perspectiva. Brasília: MEC. Ministério da Educação, ABEAS: Lavras: ESAL/FAEPE, 1988. 236p.

22. SOUTO, P.C. Acumulação e decomposição da serapilheira e distribuição de organismos edáficos em área de caatinga na Paraíba, Brasil. 2006. 150f. Tese. (Doutorado em Agronomia) - Centro de Ciências Agrárias, Universidade Federal da Paraíba, Areia, PB.

23. SOUZA, L.A.G.; SILVA, M.F.; MOREIRA, F.M.S. Associações rizóbio-leguminosas na Amazônia. In: Vinte anos de contribuição do INPA à pesquisa agronômica no Trópico Úmido. INPA, 1997. p. 193-220.

24. TOLAANDER J. F.; ARTURSSON, V.; PAUL, L. R.; JANSSON, J. K.; FINLAY, R. D. Attachment of different soil bacteria to arbuscular mycorrhizal fungi is determined by hyphal vitality and fungal species. FEMS Microbiology Letters, Amsterdam, v. 254, p. 34-40, 2006. 
25. WEAVER, R. W.; FREDERICK, L. R. Rhizobium. In: PAGE, A. L.; MILLER, R. H.; KEENEY, D. R. (Ed.). Methods of soil analysis: chemical and microbiological prop erties. 2nd ed. Ma d i s o $n$ : Ame r i c a n S o c i e t y of Agronomy, 1982. part 2, p. 1043-1070.

26. ZILLI, J.L.E. Caracterização e seleção de estirpes de rizóbio para inoculação de caupi (Vigna unguiculata (L.) Walp.) em áreas do cerrado. Seropédica: Universidade Federal Rural do Rio de Janeiro, 2001. 137 p. Dissertação Mestrado. 